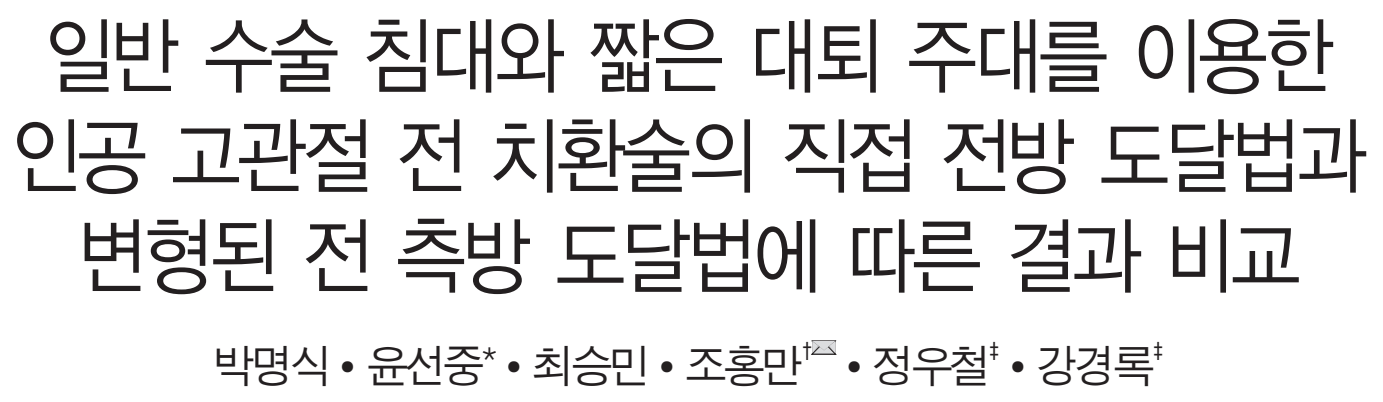

호성전주병원 정형외과, ${ }^{\star}$ 전북대학교 의학전문대학원 정형외과학교실, ${ }^{`}$ 광주보훈병원 정형외과, ${ }^{\ddagger}$ 성가롤로병원 정형외과

\title{
Comparison of the Outcomes after Primary Total Hip Arthroplasty Using a Short Stem between the Modified Anterolateral Approach and Direct Anterior Approach with a Standard Operation Table
}

\author{
Myung-Sik Park, M.D., Sun-Jung Yoon, M.D.*, Seung-Min Choi, M.D., Hong-Man Cho, M.D. ${ }^{\dagger}$, \\ Woochull Chung, M.D. ${ }^{\ddagger}$, and Kyung-Rok Kang, M.D. ${ }^{\ddagger}$
}

Department of Orthopedic Surgery, Hoseung Hospital, ${ }^{\star}$ Department of Orthopaedic Surgery, Chonbuk National University Medical School, Jeonju,

${ }^{\dagger}$ Department of Orthopedic Surgery, Gwangju Veterans Hospital, Gwangju, ${ }^{\ddagger}$ Department of Orthopedic Surgery, St. Carollo Hospital, Suncheon, Korea

Purpose: Total hip arthroplasty was performed using a direct anterior approach (DAA) on an ordinary operation table and a short femoral stem. The clinical radiographic results were evaluated by a comparison with those performed using the modified hardinge (anterolateral approach, ALA) method.

Materials and Methods: From January 2013 to November 2015, 102 patients who underwent total hip arthroplasty using DAA (DAA group) and the same number of patients using ALA (ALA group), both performed by a single surgeon, were compared and analyzed retrospectively. The operation time and amounts of bleeding were compared, and the improvement in post-operative pain, ambulatory capacity and functional recovery of the hip joint were checked. The location of insertion of the acetabular cup and femoral stem were evaluated radiologically, and the complications that occurred in the two groups were investigated.

Results: The amount of bleeding was significantly smaller in the DAA group ( $\mathrm{p}=0.018$ ). Up to 3 weeks postoperatively, recovery of hip muscle strength was significantly higher in the DAA group (flexion/extension strength $p=0.023$, abduction strength $p=0.031$ ). The Harris hip score was significantly better in the DAA group for up to 3 months $(p<0.001)$ and the Koval score showed significantly better results in the DAA group up to 6 weeks $(p \leq 0.001)$. The visual analogue scale score improvement was significantly higher in the DAA group by day 7 ( $p=0.035)$. The inclination angle $(p<0.001)$ and anteversion angle $(p<0.001)$ of the acetabular cup were located in the safe zone of the DAA group more than in the ALA group, and there was no statistically significant difference in the position of the femur stem and leg length difference. During surgery, two cases of greater trochanter fracture occurred in the DAA group ( $\mathrm{p}=0.155)$.

Conclusion: The DAA performed in the ordinary operation table using a short femoral stem showed post-operative early functional recovery. Because a simple to use fluoroscope was used during surgery with an anatomical position familiar to the surgeon, it is considered to be useful for the insertion of implants into the desired position and for an approach that is useful for the prevention of leg length differences.

Key words: total hip arthroplasty, direct anterior approach, anterolateral approach, short femoral stem, operating tables

Received August 7, 2018 Revised October 2, 2018 Accepted October 2, 2018

Correspondence to: Hong-Man Cho, M.D.

Department of Orthopedic Surgery, Gwangju Veterans Hospital, 99 Cheomdanwolbong-ro, Gwangsan-gu, Gwangju 62284, Korea

TEL: +82-62-602-6162 FAX: +82-62-602-6936 E-mail: chm1228@hanmail.net ORCID: https://orcid.org/0000-0001-5160-2640 
Hip Arthroplasty Using a DAA with a Standard Operation Table

\section{서 론}

인공 고관절 전 치환술(total hip arthroplasty, THA)은 집도의의 선 호와 숙련도에 따라 다양한 도달법으로 시행되고 있으며 ${ }^{1-5)}$ 여러 도달법 중 직접 전방 도달법(direct anterior approach, DAA)은 연 부조직의 손상이 적은 도달법 중의 하나이다. DAA는 고관절 전 방의 신경과 근육 사이의 간격을 이용하는 방법으로 최근 우수한 결과가 보고되면서 관심이 증가하고 있다. ${ }^{677} \mathrm{DAA}$ 는 근위 대퇴부 에 부착된 근육의 분리나 손상이 없이 수술이 가능하고, 수술 후 조기에 통증 개선과 보행 능력 회복이 이루어진다는 점 이외에도 입원 기간이 단축되고 의료비 지출이 감소하는 등의 많은 장점이 있으며, 고관절의 안정성에도 기여하여 탈구 등 불안정에 의하여 발생하는 합병증의 발생도 적다고 알려져 있다. ${ }^{7.8}$

그러나 경험이 많은 고관절 전문 의사라고 하더라도 $\mathrm{DAA}$ 를 새로 시작하는 데는 몇 가지 어려운 점이 있다. 대퇴골 근위부의 완전한 노출이 어려워 수술 중 대퇴골 골절과 대퇴 주대의 부정 위 삽입 위험성이 있으며, 과도한 견인으로 인한 피부의 긴장으 로 피부 관련 합병증이 발생할 수 있기 때문이다. 여러 연구들은 대퇴부 준비 과정을 용이하게 하여 이러한 문제점을 해결하고자 하지의 견인, 신전, 회전이 가능한 특별한 견인 침대(specialized traction table) ${ }^{6}$ 와 견인기 및 확공기(offset broach or specially manufactured Hohmanns)를 갖추어야 한다고 보고한 바 있다.9.10) 저 자들은 전 측방 도달법(modified hardinge; anterolateral approach, ALA)에 숙련되어 있는 고관절 전문 의사로서 일반 수술용 침대 하에서 DAA THA를 길이가 짧은 대퇴 주대(short stem)를 이용하
여 시행하고, 임상적 및 영상 의학적 결과를 비교하여 알아보고 자 하였다.

\section{대상 및 방법}

\section{1. 연구 대상 및 방법}

\section{1) 연구 대상}

본 연구는 광주보훈병원 연구윤리 위원회로부터 검토 및 승인을 받았다(GJVH-IRB No. 2017-12-4). 저자는 ALA THA를 10년 이 상 집도한 경험이 있는 고관절 전문의로서 2013년 1월부터 DAA $\mathrm{THA}$ 를 총 157예 시행하였다. 숙련도를 감안하여 초기 50예 ${ }^{11}$ 를 제외한 107 명의 환자 중 2년 이상 추시가 가능하였던 102명(102 예, 남성 54예 여성 48예)의 환자(DAA group)와 가장 최근에 ALA 로 수술한 환자 중 DAA group과 성별, 체질량 지수(body mass index, BMI), 진단명, 마취 및 수술 위험도, 보행 정도 등을 비교하 여 선발한 동수의 대조군(ALA group)을 후향적으로 비교 분석하 였다. 수술 당시의 평균 연령은 DAA group은 55.31세(25-77세), ALA group은 57.75세(29-80세)였고, 평균 추시 기간은 각각 2.31 년(2.0-3.5년)과 5.25년(4.0-7.5년)이었다. 두 group의 전체의 평 균 BMI에 유의한 차이는 없었다(DAA group: $24.80 \pm 3.44 \mathrm{~kg} / \mathrm{m}^{2}$, ALA group: $\left.24.45 \pm 3.17 \mathrm{~kg} / \mathrm{m}^{2} ; \mathrm{p}=0.377\right)$. 수술 전 진단으로 DAA group은 고관절 이형성증에 의한 골관절염(27예), 비구 골절에 의 한 외상성 고관절염(4예), 퇴행성 고관절염(26예), 대퇴골두 무혈 성 괴사(45예)가 있었고, ALA group에서는 고관절 이형성증에 의 한 골관절염(25예), 비구 골절에 의한 외상성 고관절염(3예), 퇴행

Table 1. Demographic Data and Intraoperative Characteristics

\begin{tabular}{|c|c|c|c|}
\hline Characteristic & DAA group $(n=102)$ & ALA group $(n=102)$ & $p$-value \\
\hline Sex (male:female) & $54: 48$ & $57: 45$ & 0.574 \\
\hline Age (yr) & $55.31(25-77)$ & $57.75(29-80)$ & 0.607 \\
\hline Follow-up duration (yr) & $2.31(2.0-3.5)$ & $5.25(4.0-7.5)$ & 0.139 \\
\hline $\mathrm{BMI}\left(\mathrm{kg} / \mathrm{m}^{2}\right)$ & $24.80 \pm 3.44$ & $24.45 \pm 3.17$ & 0.377 \\
\hline \multicolumn{4}{|l|}{ Preoperative diagnosis } \\
\hline Dysplastic hip osteoarthritis & 27 & 25 & 0.957 \\
\hline Traumatic osteoarthritis & 4 & 3 & \\
\hline Degenerative hip joint osteoarthritis & 26 & 26 & \\
\hline Avascular necrosis of the femoral head & 45 & 48 & \\
\hline \multicolumn{4}{|l|}{ Muscle strength (preoperation) } \\
\hline Abduction (kg) & $11.0 \pm 3.1$ & $12.0 \pm 4.6$ & 0.487 \\
\hline Leg press $(\mathrm{kg})$ & $72.0 \pm 26.3$ & $75.0 \pm 23.0$ & 0.744 \\
\hline Total hospital periods (d) & $12.3(7-21)$ & $18.5(7-25)$ & 0.035 \\
\hline
\end{tabular}

Values are presented as number only, median (range), or mean \pm standard deviation. DAA, direct anterior approach; ALA, anterolateral approach; BMI, body mass index. 
Myung-Sik Park, et al.

성 고관절염(26예), 대퇴골두 무혈성 괴사(48예)가 있었다(Table 1). 두 군 모두에서 수술 중 영상 증폭기(fluoroscope)를 사용하여 삽입된 비구 컵과 대퇴 주대의 위치를 확인하였다.

\section{2) 직접 전방 도달법 group에서 대퇴 주대의 삽입 전 처치와 수술 방법}

$\mathrm{DAA}$ 를 통해 대퇴골두가 노출되면, 두 번에 나누어 대퇴 경부를 절단하고 대퇴골두를 제거하였다. 수술하는 하지의 침대 다리 부 분을 바닥으로 향하게 한 후 고관절은 신전과 외회전, 슬관절은 과굴곡시켜 "figure 4" 자세를 만들었다. 근위 대퇴골 주변 연부조 직의 긴장도를 느끼면서 대퇴골 대전자와 경부 주변의 연부조직 (joint capsule, piriformis/gemellus/obturator internus muscle)을 단 계적으로 유리해 가면서, 대퇴 주대 삽입 부분이 충분히 노출되 도록 하였다. 삽입 부분이 충분히 노출되면, 대퇴 주대의 부정 정 렬을 방지하기 위하여 rounger를 이용하여 골수강 중심의 해면골 일부를 먼저 제거하고, 골수강 탐색기(canal finder)를 삽입하여 적 절한 위치와 방향을 확인한 후 rasping과 주대를 삽입하였다.

\section{3) 비구 컵과 대퇴 주대}

수술은 한 명의 고관절 전문의에 의해 시행되었다. 두 group 모 두에서 무시멘트 비구 컵과 대퇴 주대, 세라믹-세라믹 관절면 (ceramic to ceramic bearing, 32 or $36 \mathrm{~mm}$ Biolox delta; CeramTec, Plochingen, Germany)을 사용하였는데, DAA group에서는 무시 멘트 비구 컵(Delta PF cup; Lima Co., Udine, Italy)과 무시멘트형 의 짧은 길이 대퇴 주대(Minima stem, $131^{\circ}$ neck-shaft angle; Lima Co.)를 사용하였고, ALA group에서는 무시멘트 비구 컵(Delta PF cup; Lima Co.)과 무시멘트형의 표준형 대퇴 주대(C2 stem, rectangular cross-sectional, double tapered; Lima Co.)를 사용하였다.

\section{2. 임상적 평가}

\section{1) 수술 과정 평가}

수술 중 출혈량과 수술 시간, 그리고 수술 후 수혈량과 총 입원 기 간을 비교하였다. 수혈은 수술 중 출혈량과 수술 후 측정한 배액 량을 더하여 2,000 $\mathrm{ml}$ 가 넘는 경우와 혈색소 수치가 $6 \mathrm{~g} / \mathrm{dl}$ 이하인 경우, 혈색소 수치가 $8 \mathrm{~g} / \mathrm{dl}$ 이하이면서 심혈관 질환, 신부전, 뇌혈 관 질환 및 보상 기전에 제한이 있을 것으로 추정되는 위험 환자 와 저산소증을 유발할 만한 증상(심계항진, 저혈압, 심근 허혈이 의심되는 심전도 소견, 유산 산증)을 보이는 경우에 시행하였다. 출혈량은 수술 중 사용한 세척액을 제외한 배액관에 배액된 양과 수술 전후로 무게를 측정한 거즈와 수술 후 측정된 배액의 총량 을 더하여 계산하였다. 수술 시간은 피부 절개부터 봉합의 종료 로 평가하였다.

\section{2) 근력 회복 정도 측정}

근력은 고관절의 굴곡/신전력과 외전력을 측정하였다. 환자의 치 료 과정과 무관한 2 명의 재활 치료사에 의해 수술 후 2 일, 8 일, 3 주, 6주, 3개월에 시행되었다. 굴곡/신전력의 측정은 leg-press ergometer를 이용하여 하지의 완전 신전 상태에서 $10 \mathrm{~kg}$ 단위로 저 항을 이기며 고관절과 슬관절을 90 도까지 굴곡시킨 후 완전히 하 지를 신전시키는 것으로 측정하였고, 환자가 더 이상 할 수 없을 때 검사가 종료되었다. 외전력의 측정은 측정하는 다리를 정해진 위치까지 $(30 \mathrm{~cm})$ 들어 올리고 수평-외전(horizontal abduction)시 키는 것으로 측정하였고, 단계별로 $2.5 \mathrm{~kg}$ 씩 증량하였는데 환자가 더 이상 외전 운동을 할 수 없을 때 검사가 종료되었다. 수술을 시 행하기 2주 전에 같은 방법으로 근력을 측정하여 수술 후 측정한 결과와 비교하였다.

\section{3) 수술 후 기능 회복과 통증 호전 평가}

수술 후 기능 회복을 평가하기 위하여 Harris hip score (HHS) ${ }^{12)}$ 와 Koval score ${ }^{13)}$ 를 수술 후 2주, 6주, 3개월, 6개월, 12개월, 이후에 는 1년 간격으로 평가하였고, 통증은 visual analogue scale (VAS, 0-100)을 이용하여 수술 후 2일, 7일, 2주, 6주, 3개월, 6개월, 12 개 월, 이후에는 1 년 간격으로 평가하였다.

\section{3. 영상의학적 평가}

고관절 전후면 영상에서 비구 컵의 경사각(inclination angle)과 전 염각(anteversion angle)을 측정하였고, ${ }^{14}$ 삽입된 대퇴 주대의 정렬 은 대퇴 골수강의 해부학적 정렬에 대해 5 도를 기준으로 내반, 중 립, 외반위로 분류하였다. ${ }^{11)}$ 하지의 길이는 양측 하지를 15 도 내회 전시킨 상태에서 촬영한 고관절의 전후면 영상에서 골반 골의 눈 물방울(tear drop)의 하연(inferior margin)과 소전자의 중심(midline of lesser trochanter)을 이용하여 측정하였다. 영상의학적 평가는 수술과 무관한 2 명의 연구원에 의해 시행되었고, 두 관찰자의 관 찰자 내(K1) 및 관찰자 간(K2) 신뢰도는 각 항목별로 모두 신뢰할 수 있는 수준이었다(K1=0.88, K2=0.81).

\section{4. 통계분석}

통계적인 분석은 PASW ver. 18.0 (IBM Corp., Armonk, NY, USA) 프로그램을 이용하여 연속형 변수에 대해 independent t-test와 paired t-test, 범주형 변수에 대해 카이제곱 검정이나 Fisher의 정 확 검정을 사용하였다. 모든 분석의 통계적 유의 수준은 $\mathrm{p}$ 값이 0.05 미만인 경우로 하였다. 두 관찰자의 관찰자 내(K1) 및 관찰자 간(K2) 신뢰도 측정을 위하여 kappa coefficient test를 적용하였다. 
Hip Arthroplasty Using a DAA with a Standard Operation Table

\section{결 과}

\section{1. 수술과 연관된 항목 평가}

평균 수술 시간은 DAA group에서 85.5분(45-115분), ALA group 에서 83.2분(45-125분)이었고 $(\mathrm{p}=0.871)$, 수혈량은 1.02 pack (0-3 pack)과 1.14 pack (0-3 pack) ( $\mathrm{p}=0.078)$ 으로 두 군 간에 유의한 차 이는 없었다. 하지만 출혈량은 DAA group에서 $763.2 \mathrm{ml}$ (330$1,630 \mathrm{ml})$ ALA group에서 $919.7 \mathrm{ml}(380-1,850 \mathrm{ml})(\mathrm{p}=0.018)$ 이었고, 평균 입원 기간은 각각 12.3 일(7-21일)과 18.5 일(7-25일)로 유의한 차이가 있었다( $\mathrm{p}=0.035)$ (Table 1).

\section{2. 임상적 결과}

1) 근력 측정 결과

고관절의 굴곡/신전력과 외전력의 회복은 DAA group에서 수술 후 2일부터 3주까지는 더 유의하게 개선되었으나 수술 후 6 주와 3 개월에는 두 군 간에 유의한 차이는 보이지 않았다(Table 2).

\section{2) 수술 후 기능 및 통증 회복 결과}

HHS score를 이용한 고관절 기능 평가 비교에서 3개월까지 두 군 간에 유의한 차이가 있었고, 6 개월부터는 차이가 없었다. 수술 후 보행 능력을 Koval score로 측정하였는데, 수술 후 2주(DAA, 2.24 $\pm 0.29 / A L A, 3.41 \pm 0.15 ; \mathrm{p}=0.014$ )와 6주(DAA, $1.90 \pm 0.30 / A L A$, $2.57 \pm 0.64 ; \mathrm{p}<0.001)$ 에 유의한 차이가 있었고, 수술 후 3개월부터 는 유의한 차이가 없었다( $\mathrm{p}=0.157)$. VAS score를 이용하여 측정한 통증의 정도는 수술 후 7일까지 유의한 차이가 있었고(DAA, 69.2 \pm 9.9/ALA, 73.9 $\pm 10.1 ; \mathrm{p}=0.035$ ) 2주부터는 유의한 차이가 없었다
Table 3. Pain and Functional Measurement in the Two Groups

\begin{tabular}{|c|c|c|c|}
\hline Variable & $\begin{array}{l}\text { DAA group } \\
(n=102)\end{array}$ & $\begin{array}{l}\text { ALA group } \\
(n=102)\end{array}$ & $p$-value \\
\hline \multicolumn{4}{|l|}{ VAS score } \\
\hline 7 days & $69.2 \pm 9.9$ & $73.9 \pm 10.1$ & 0.035 \\
\hline 2 weeks & $42.1 \pm 3.1$ & $43.9 \pm 1.9$ & 0.594 \\
\hline 6 weeks & $20.1 \pm 4.3$ & $21.7 \pm 4.1$ & 0.341 \\
\hline 3 months & $19.8 \pm 5.1$ & $20.4 \pm 4.9$ & 0.518 \\
\hline 6 months & $10.8 \pm 6.7$ & $9.3 \pm 5.6$ & 0.412 \\
\hline 1 year & $4.1 \pm 6.6$ & $6.5 \pm 6.3$ & 0.767 \\
\hline 2 years & $3.0 \pm 1.7$ & $2.9 \pm 1.8$ & 0.515 \\
\hline \multicolumn{4}{|c|}{ Harris hip score } \\
\hline 2 weeks & $78.85 \pm 6.64$ & $73.12 \pm 5.95$ & 0.004 \\
\hline 6 weeks & $82.15 \pm 6.93$ & $78.76 \pm 2.11$ & $<0.001$ \\
\hline 3 months & $85.48 \pm 5.51$ & $81.08 \pm 3.96$ & $<0.001$ \\
\hline 6 months & $88.19 \pm 5.23$ & $87.21 \pm 3.76$ & 0.289 \\
\hline 1 year & $93.23 \pm 3.45$ & $91.65 \pm 3.75$ & 0.474 \\
\hline 2 years & $95.20 \pm 3.09$ & $94.42 \pm 2.88$ & 0.694 \\
\hline \multicolumn{4}{|l|}{ Koval score } \\
\hline 2 weeks & $2.24 \pm 0.29$ & $3.41 \pm 0.15$ & 0.014 \\
\hline 6 weeks & $1.90 \pm 0.30$ & $2.57 \pm 0.64$ & $<0.001$ \\
\hline 3 months & $1.32 \pm 0.51$ & $1.84 \pm 0.59$ & 0.157 \\
\hline 6 months & $1.26 \pm 0.17$ & $1.37 \pm 0.67$ & 0.622 \\
\hline 1 year & $1.24 \pm 0.93$ & $1.26 \pm 0.15$ & 0.586 \\
\hline 2 years & $1.03 \pm 0.57$ & $1.17 \pm 0.89$ & 0.691 \\
\hline
\end{tabular}

Values are presented as mean \pm standard deviation. DAA, direct anterior approach; ALA, anterolateral approach; VAS, visual analogue scale.

Table 2. Muscle Strength Measurement in the Two Groups

Preoperative 2 weeks muscle strength (\% compared with preoperative value)

Leg press

Postoperative 8 days

Postoperative 3 weeks

Postoperative 6 weeks

Postoperative 3 months

Abduction strength

Postoperative 2 days

Postoperative 8 days

Postoperative 3 weeks

Postoperative 6 weeks

Postoperative 3 months
Postoperative 2 days

$\begin{array}{rrr}80(70-100) & 49(35-55) & 0.001 \\ 89(85-115) & 63(50-75) & 0.001 \\ 94(85-120) & 81(65-90) & 0.023 \\ 99(90-130) & 91(80-100) & 0.874 \\ 113(95-135) & 112(90-150) & 0.882 \\ 80(65-100) & 57(35-60) & \\ 94(100-120) & 69(50-85) & 0.035 \\ 98(100-130) & 81(75-100) & 0.028 \\ 107(100-135) & 100(85-110) & 0.923 \\ 129(115-160) & 127(100-135) & 0.817\end{array}$

Values are presented as median (range). DAA, direct anterior approach; ALA, anterolateral approach. 
Myung-Sik Park, et al.

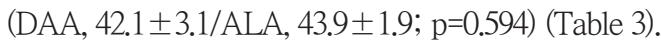

\section{3. 영상의학적 결과}

비구 컵의 경사각과 전염각은 DAA group에서 43.74 23.75 도와

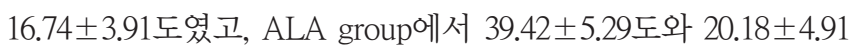
도였다. Lewinnek safe zone ${ }^{14)}$ 에 따라 측정한 안정 범위에 포함되 지 않은 예는 DAA group에서 1예, ALA group에서 7예로 두 군 간 에 유의한 차이 $(\mathrm{p}=0.030)$ 가 있었다. 최종 추시에서 비구 컵의 회전 이동이나 수직 이동은 전 예에서 관찰할 수 없었고, $2 \mathrm{~mm}$ 이상의
방사선 투과성 선이나 경화선은 관찰되지 않았다. 대퇴골의 전후 면상과 측면상에서 측정한 대퇴 주대의 위치(anteroposterior view, $\mathrm{p}=0.517$; lateral view, $\mathrm{p}=0.397$ )와 하지 길이(DAA, 2.35 $\pm 3.77 / \mathrm{ALA}$, $2.36 \pm 4.45 ; \mathrm{p}=0.26$ )의 차이에 통계적 유의한 차이는 없었다. 추시 중 대퇴 주대의 위치가 변한 예는 없었으며, 치환물 이완은 관찰 되지 않았다. 불안정 pedestal이 형성된 예는 없었으며, 골용해 및 수직 침강은 보이지 않았다(Fig. 1, Table 4).
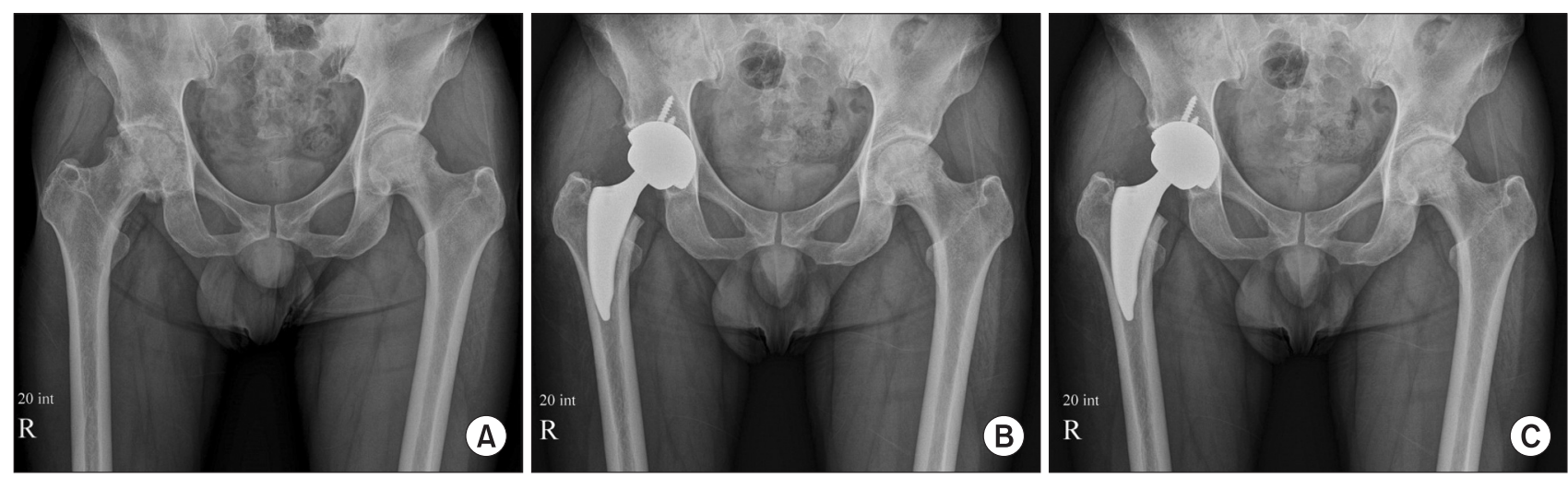

Figure 1. Preoperative and postoperative radiographs of the right hip of a male who was 65 years old at the time of the right primary total hip replacement. (A) Preoperative anteroposterior radiograph demonstrating osteoarthritis of the hip with partial loss of the joint space and formation of osteophytes. (B, C) Anteroposterior radiographs at 2 years after total hip replacement with use of a cementless short stem (Minima stem, $131^{\circ}$ neckshaft angle; Lima Co., Udine, Italy) and ceramic-on-cerami acetabular component (Delta PF cup; Lima Co.). Note the excellent osseointegration and absence of radiolucent lines at the implant-bone interface.

Table 4. Radiologic Measurement in the Two Groups

\begin{tabular}{|c|c|c|c|}
\hline Variable & DAA group ( $n=102$ ) & ALA group $(\mathrm{n}=102)$ & $p$-value \\
\hline Acetabular cup (cementless) & Delta PF cup & Delta PF cup & \\
\hline Femur stem (cementless) & Minima stem & C2 stem & \\
\hline Bearing & Ceramic-ceramic & Ceramic-ceramic & \\
\hline Acetabular cup anteversion $\left(^{\circ}\right)$ & $16.74 \pm 3.91$ & $20.18 \pm 4.91$ & \\
\hline Acetabular cup inclination $\left(^{\circ}\right)$ & $43.74 \pm 3.75$ & $39.42 \pm 5.29$ & \\
\hline \multicolumn{4}{|l|}{ Femoral stem axis } \\
\hline \multicolumn{4}{|l|}{ Anteroposterior radiograph } \\
\hline Neutral & $96(94.1)$ & $97(95.1)$ & 0.517 \\
\hline Varus & $6(5.9)$ & $4(3.9)$ & \\
\hline Valgus & $0(0)$ & $1(1.0)$ & \\
\hline \multicolumn{4}{|l|}{ Lateral radiograph } \\
\hline Neutral & 98 (96.1) & $100(98.0)$ & 0.397 \\
\hline Varus & $4(3.9)$ & $1(1.0)$ & \\
\hline Valgus & $0(0)$ & $1(1.0)$ & \\
\hline Leg length discrepancy (mm) & $2.35 \pm 3.77$ & $2.36 \pm 4.45$ & 0.26 \\
\hline
\end{tabular}

Values are presented as mean \pm standard deviation or number (\%). DAA, direct anterior approach; ALA, anterolateral approach. 

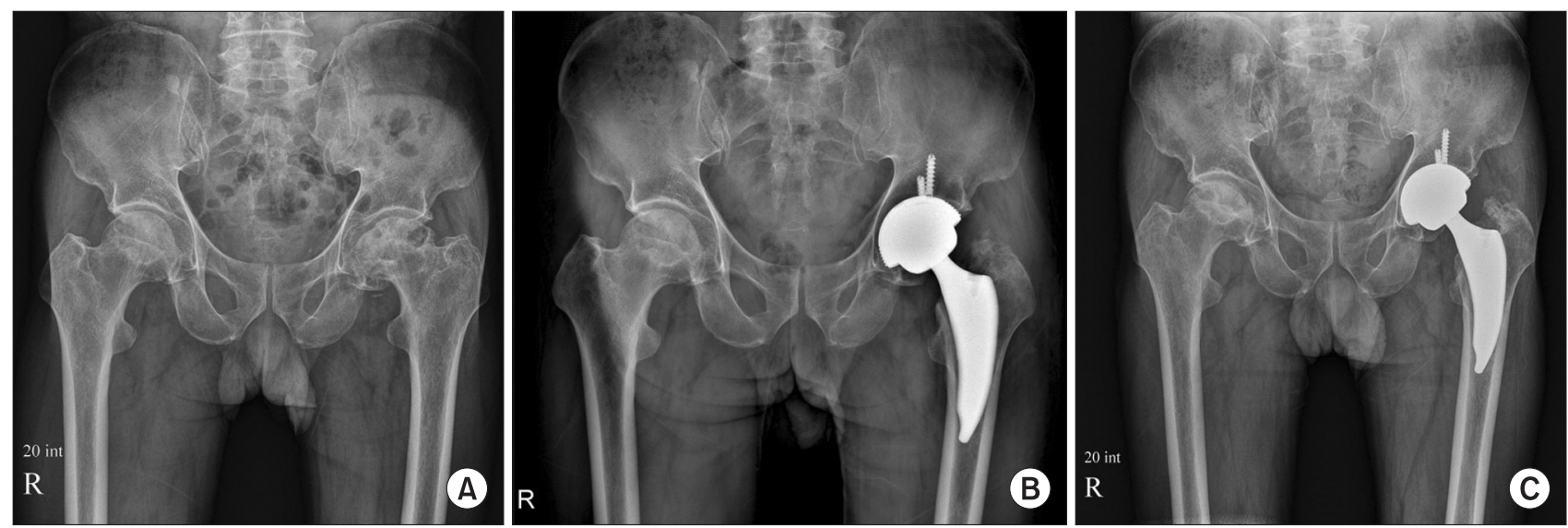

Figure 2. (A) Preoperative radiograph of the left hip of a male who was 68 years old at the time of the left primary total hip replacement. Anteroposterior radiograph demonstrating avascular necrosis of the femoral head with partial collapse and formation of osteophytes. (B) Postoperative anteroposterior radiograph after total hip replacement using a cementless short stem (Minima stem, $131^{\circ}$ neck-shaft angle; Lima Co., Udine, Italy) and ceramic-on-ceramic acetabular component (Delta PF cup; Lima Co.). Greater trochanter tip fracture occurred during femoral stem insertion. (C) Note the excellent osseointegration and absence of radiolucent lines at the implant-bone interface and united greater trochanter tip fracture.

Table 5. Complications

\begin{tabular}{lccc}
\multicolumn{1}{c}{ Complication } & $\begin{array}{c}\text { DAA group } \\
(\mathrm{n}=102)\end{array}$ & $\begin{array}{c}\text { ALA group } \\
(\mathrm{n}=102)\end{array}$ & $\mathrm{p}$-value \\
$\begin{array}{l}\text { Greater trochanteric fracture } \\
\text { (intraoperation) }\end{array}$ & 2 & 0 & 0.155 \\
$\begin{array}{l}\text { Inguinal pain (within 4 months) } \\
\text { Wound revision }\end{array}$ & 4 & 0 & 0.043 \\
$\begin{array}{l}\text { Lateral femoral cutaneous } \\
\text { nerve symptom }\end{array}$ & 1 & 0 & 0.316 \\
$\begin{array}{l}\text { Periprosthetic fracture } \\
\text { (postoperation) }\end{array}$ & 0 & 0 & 0.316 \\
$\quad \begin{array}{l}\text { Dislocation } \\
\text { Gluteal lurch gait }\end{array}$ & 0 & 1 & 0.316 \\
\hline
\end{tabular}

Values are presented as number only. DAA, direct anterior approach; $\mathrm{ALA}$, anterolateral approach.

\section{4. 합병증}

1) 직접 전방 도달법 group의 합병증

수술 중 2 명의 환자에게서 대전자 골절이 발생하였는데, 주대 안 정성에 영향이 없는 대전자 첨부의 골절로 추시 관찰 기간 동안 특별한 불편함의 호소는 없어 보존적으로 치료하였다(Fig. 2). 2명 의 환자가 수술 후 보행을 시작하면서부터 간헐적인 전하장골능 (anterior inferior iliac spine)의 통증을 호소하였는데, 이는 수술 중 비구부 노출을 위해 사용한 곡선형의 견인기(curved retractor)에 의한 대퇴직근의 손상(rectus femoris muscle)으로 추정되었다. 한 명의 환자는 소염 진통제를 사용하여 수술 후 6주부터 호전되었 고, 호전이 없었던 나머지 한 명은 수술 후 4개월에 고관절 관절 낭 전방에 국소 스테로이드 주사를 시행한 후 호전되었다. 절개
근위부의 피부에 괴사가 발생하였던 1 예는 BMI가 $30 \mathrm{~kg} / \mathrm{m}^{2}$ 이상 이었던 환자로, 수술 후 3주에 절제 봉합을 시행하여 호전되었다. 대퇴 외측의 감각 저하와 이상 감각을 호소하였던 환자 1예는 대 퇴 외측 경피 신경(Lateral femoral cutaneous nerve)의 압박으로 발 생한 것으로 추정되었는데, 특별한 치료 없이 수술 후 6주에 호전 되었다(Table 5).

\section{2) 전 측방 도달법 group의 합병증}

수술 후 3개월에 보행 중 낙상으로 인한 인공 관절 주변 골절 환 자가 1 예 있었으나 대퇴 주대의 안정성에 영향이 없다고 판단하 여 보존적 치료를 시행하였고, 수상 후 10 주에 호전되었다. 음주 후 넘어지고 인공 고관절 탈구가 1예 발생하여 외전 보조기를 6주 착용시켰으며, 이후 탈구의 재발은 없었다. 이 외에 수술 후 최종 추시까지 보행이 둔탁하다고 호소하는 환자가 1예 있었다(Table 5).

\section{고 찰}

$\mathrm{DAA}$ 는 다른 방법의 도달법과 비교할 때 대퇴골 근위부에 부착 된 근육을 보존하고 연속성의 손상을 방지함으로써 조기 보행 능 력 회복과 짧은 입원 기간 등 여러 가지 장점이 있다. ${ }^{7,8)}$ ALA에 숙 달되어 있는 저자들의 연구에서도 DAA group이 수술 후 통증 개 선과 기능 및 보행 능력이 유의하게 조기에 회복되는 결과를 보 여 DAA THA는 여러 정형외과 의사들이 시도해 볼 만한 유용한 방법으로 생각되었다. 그러나 DAA는 많은 장점에도 불구하고 전 세계적으로 소수의 정형외과 의사(10\%)만이 사용하고 있다고 알 려져 있다. ${ }^{15)}$ 왜냐하면 경험 많은 고관절 전문 의사라고 하더라 도 $\mathrm{DAA}$ 를 처음 시작하고 익숙해지는 과정에 몇 가지 어려운 점 
Myung-Sik Park, et al.

이 있기 때문이다. 먼저 대퇴 주대 삽입을 위한 준비 과정이 다른 도달법과 비교하여 상대적으로 어려워서 이로 인한 수술 중 대퇴 골 골절이나 대퇴 주대의 부정위 삽입 등과 같은 합병증이 발생 할 수 있는 위험성이 있으며, 이외에도 DAA를 용이하게 수행하 기 위하여 대퇴골 근위부를 들어 올릴 수 있는 고가의 특수한 견 인 침대난 특별한 확공기(offset broach), 견인기(Hohmann)와 같 은 특수 장비를 갖추어야 하는 어려움이 있다.910) 특수한 견인 침 대를 사용하지 않고 일반 수술 침대하에서 시행하는 DAA THA 는 대퇴 주대 삽입을 위한 전 처치 과정이 매우 까다롭다고 알려 져 있다. 왜냐하면 대퇴골 근위부를 충분히 들어 올려야만 전 처 치와 주대 삽입이 용이한데, 앙와위 자세에서 대퇴부를 충분히 들어 올리기가 쉽지 않기 때문이다.

저자들은 먼저 수술하는 하지의 침대 다리 부분을 바닥으로 구 부리고, 하지를 “figure 4"와 같이 과신전 및 외회전시켜 대퇴골 근위부를 일차로 노출시켰다.) 그리고 긴장도를 확인하면서 대 퇴골 대전자의 내측과 경부를 따라 연부조직을 순차적으로 유리 시켜 나갔다. 이 과정에 만나게 되는 후방 회선 혈관(posterior circumflex vessel)들은 육안으로 확인하고 전기 소작으로 출혈을 방

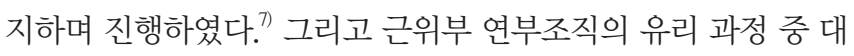
퇴골을 내측으로 잡아당기는 역할을 하여 고관절의 안정성에 기 여하는 obturator externus muscle에 손상을 주지 않도록 주의하였 다. Post 등 ${ }^{16}$ 이 권유한 방식대로 canal finder를 이용하여 적절한 방향과 위치를 먼저 확인하고 대퇴 골수강 확공 후 대퇴 주대를 삽입함으로써 대퇴골 천공이나 대퇴 주대의 부정 정렬이 발생하 지 않도록 하였다.

일반 수술 침대 위의 앙와위 자세는 환자를 정확한 전후면 자 세(true anteroposterior position)로 만들 수 있고, 대부분의 의사들 에게 익숙한 해부학적 자세이며, 양 하지의 길이를 쉽게 측정할 수 있다는 장점이 있다. 이외에도 수술 중 영상 증폭기의 사용을 용이하게 함으로써 수술 집도의에게 삽입할 인공 관절물의 위치 를 예측하고 정하는 데 도움을 줄 수 있다. 비구 컵을 위한 확공과 삽입 과정을 수술 진행 중에도 편리하게 확인할 수 있어 수술자 가 의도한 위치로 정확히 비구 컵을 삽입할 수 있다는 장점이 있 다. 그리고 다양한 해부학적 표지(land mark)를 이용하여 양 하지 의 길이를 확인해 볼 수 있다는 점도 있어 수술 후 발생 가능한 하 지 부동의 예방에도 도움이 된다. ${ }^{17}$ 대조적으로 ALA는 측와위에 서 시행되므로 수술 중 영상 증폭기의 사용 과정이 DAA만큼 간 편하지는 않다. 영상 증폭기가 수술 침대 주변을 회전하면서 촬 영해야 하므로 수술 부위의 오염 위험성이 있고, 환자의 전후면 상이 정확한 전후면상이라고(true anteroposterior view) 확정할 수 없으며, 수술하는 반대편 하지가 고정되어 있으므로 DAA처럼 양 하지의 길이를 비교하는 데 다양한 해부학적 표지를 이용할 수 없기 때문이다. ${ }^{710)}$ 인공 관절물의 위치에 대한 저자들의 연구 결 과에서도 DAA group이 유의하게 안정적인 위치로 삽입된 것으

로 확인되었다. THA 후 하지 부동과 관련된 합병증으로는 보행 장애, 신경 손상, 허리 통증, 고관절 불안정 등이 있고, 때로는 외 과적 교정이 필요하기도 하여 수술 중 집도의는 이의 예방을 위 하여 많은 노력을 기울여야 한다. ${ }^{18)}$ 수술 후 하지 부동을 줄이기 위한 여러 연구에서 DAA가 유익하다는 보고들이 있고, ${ }^{10}$ 저자들 의 연구 결과에서도 $5 \mathrm{~mm}$ 이상의 하지 부동은 그 발생이 매우 적 었다. 이는 환자의 앙와위가 의사들에게 익숙한 해부학적 자세 (anatomical position)이고 수술 중 편리하게 영상 증폭기를 사용 하여 영상을 확인해가며 수술을 진행할 수 있어 삽입물의 위치와 다리 길이를 정하는 데 도움을 주었기 때문이라고 생각되었다.

일반 수술 침대를 이용한 DAA THA에서 인공 관절 주변 골절 의 발생률은 약 $9 \%$ 라고 알려져 있는데, ${ }^{19)}$ 표준형의 대퇴 주대를 사용하는 경우에 위험성이 더 높아질 수 있고, ${ }^{20)}$ 대퇴 주대 삽입 과정에 유발 가능한 대퇴골의 대전자 골절이 가장 흔한 형태라고 알려져 있다. ${ }^{21}$ 표준형 대퇴 주대의 삽입을 위해서는 대퇴골 근 위부를 완전히 노출시키고 전방 거상을 충분히 해주어야 안정적 인 삽입이 가능한데, 노출과 전방 거상이 충분하지 않으면 주변 연부조직들이 수술자의 시야를 방해하고, 대퇴 주대의 부정 정렬 을 유발할 수 있어 rasping과 주대 삽입 과정 중 대전자 부위에 과 도한 압력을 주기 때문이다. ${ }^{21}$ 그리고 저자들은 부정 정렬된 대 퇴 주대가 대퇴 거(calcar)와 대퇴 주대의 끝부분과 접촉하는 골간

\begin{tabular}{|c|c|c|}
\hline $\begin{array}{l}\text { Approach } \\
\text { method }\end{array}$ & Pro & Contra \\
\hline \multirow[t]{6}{*}{ Anterior } & Anatomical & $\begin{array}{l}\text { Special traction table } \\
\text { required in some cases }\end{array}$ \\
\hline & $\begin{array}{l}\text { Preserves posterior } \\
\text { structures }\end{array}$ & $\begin{array}{l}\text { Lateral femoral cutaneous } \\
\text { nerve at risk }\end{array}$ \\
\hline & $\begin{array}{l}\text { Preserves abductor } \\
\text { muscles }\end{array}$ & Long learning curve \\
\hline & Low dislocation rate & \\
\hline & $\begin{array}{l}\text { Quick recovery } \\
\text { without restrictions }\end{array}$ & \\
\hline & $\begin{array}{l}\text { Easy lengthening of } \\
\text { incision }\end{array}$ & \\
\hline \multirow[t]{5}{*}{ Anterolateral } & Easy approach & $\begin{array}{l}\text { Disturbance of abductor } \\
\text { muscles }\end{array}$ \\
\hline & Short learning curve & $\begin{array}{l}\text { Superior gluteal nerve } \\
\text { ar rish }\end{array}$ \\
\hline & $\begin{array}{l}\text { Easy lengthening of } \\
\text { incision }\end{array}$ & Heterotrophic calcification \\
\hline & Wide view & \\
\hline & Low dislocation rate & \\
\hline
\end{tabular}

Table 6. Overview of the Pros and Cons between Anterior and Anterolateral Approaches to the Hip in Primary Total Hip Arthroplasty

Approach

method

Anatomical

Preserves posterior

Preserves abductor

Quick recovery

Esy lengthening of 
(diaphysis)에 더 많은 스트레스를 가하게 되므로 또 다른 대퇴골 골절의 원인이 될 수 있다고 생각하였다. 이와 같은 문제를 해결 하기 위하여 짧은 길이와 외측으로 만곡된 형태를 가진 대퇴 주 대의 사용이 주장되었고, ${ }^{19}$ 저자들도 femoral neck implants type ${ }^{22)}$ 의 짧은 대퇴 주대를 사용하여 DAA THA를 시행하였다. 저자들 은 DAA group에서 2예(1.96\%)의 수술 중 대퇴골 골절을 경험하였 는데, 이는 Berend 등 ${ }^{19}$ 의 보고에 비교하여 높은 발생률이었다. 하 지만 저자들의 2예는 모두 연구 대상 중 초기에 시행되었던 환자 들이었고, 이후로는 수술 중 인공 관절 주변 골절은 발생하지 않 고 있어 femoral neck implants type ${ }^{22)}$ 의 짧은 대퇴 주대를 이용하 여 DAA THA를 시행한다면 일반 수술 침대를 이용한다고 하더 라도 수술 중 골절의 위험성은 크지 않을 것으로 생각되었다. 하 지만 Hartford와 Knowles ${ }^{23}$ 는 BMI가 높은 비만 환자에게 시행하 는 DAA THA에서 골절 위험이 7배(odds ratio, 7.6) 이상 증가한다 고 보고한 바 있으므로, 비만한 환자를 DAA THA하는 경우에는 더욱 각별한 주의가 요할 것으로 생각하였다(Table 6). ${ }^{24)}$

본 연구는 몇 가지 제한점을 가지고 있다. 먼저 증례 수가 작고 추시 기간이 짧았으며 후향적 연구라는 점이다. 향후 더 많은 증 례를 전향적으로 장기간으로 추시 분석이 필요할 것으로 생각된 다. 그럼에도 불구하고 본 연구는 ALA에 숙달된 고관절 전문 의 사가 단독으로 수술한 대부분의 증례가 포함되었으므로 DAA를 시작하려는 많은 정형외과 의사들에게 의미 있는 보고가 될 것으 로 생각한다. 또한 향후 이루어질 추가 연구에서는 환자의 경제 적인 면과 재치환 여부 등에 대해서도 다루어져야 한다고 생각한 다. 조기 기능 회복은 환자의 의료비의 지출을 줄이며 경제 활동 으로 조기 복귀를 할 수 있기 때문에 중요한 평가 요소라고 생각 한다. 그리고 근육의 연속성에 손상 없이 수술을 시행하였으므로 재치환 시에 이로 인한 장점과 단점을 평가하는 것도 중요할 것 으로 생각한다. 또 다른 제한점은 연구 대상 환자의 BMI가 $35 \mathrm{~kg} / \mathrm{m}^{2}$ 미만으로, DAA의 합병증 발생에 있어 고위험군으로 알려진 비만 환자에 대한 분석이 충분하지 않다는 점이다. 대부분의 아시아계 국가에서는 비만도가 높은 환자가 드물어 그 수가 적은 것으로 생각이 되나 비만 환자는 수술 중과 수술 후 다양한 합병증의 발 생이 가능하다는 연구 결과가 있으므로 향후 더 많은 증례가 수 집되면 비만 환자에 대한 분석이 추가로 필요할 것으로 생각되었 다.

\section{결 론}

수술 후 조기 통증 개선과 기능 회복이라는 장점을 가진 DAA $\mathrm{THA}$ 는 길이가 짧은 대퇴 주대를 이용하면 일반 수술 침대 하에 서도 안정적으로 시행할 수 있고, 인공 관절물을 정확한 위치에 삽입할 수 있으며 하지 부동 방지에도 유용하여 추천할 만한 도 달법으로 생각된다.

\section{CONFLICTS OF INTEREST}

The authors have nothing to disclose.

\section{REFERENCES}

1. Smith-Petersen MN. A new supra-articular subperiosteal approach to the hip joint. J Bone Joint Surg. 1917;2:592-5.

2. Burwell HN, Scott D. A lateral intermuscular approach to the hip joint for replacement of the femoral head by a prosthesis. J Bone Joint Surg Br. 1954;36:104-8.

3. Harris WH. A new lateral approach to the hip joint. J Bone Joint Surg Am. 1967;49:891-8.

4. Iyer KM. A new posterior approach to the hip joint. Injury. 1981;13:76-80.

5. Hardinge K. The direct lateral approach to the hip. J Bone Joint Surg Br. 1982;64:17-9.

6. Berend KR, Lombardi AV Jr, Seng BE, Adams JB. Enhanced early outcomes with the anterior supine intermuscular approach in primary total hip arthroplasty. J Bone Joint Surg Am. 2009;91 Suppl 6:107-20.

7. Kennon RE, Keggi JM, Wetmore RS, Zatorski LE, Huo MH, Keggi KJ. Total hip arthroplasty through a minimally invasive anterior surgical approach. J Bone Joint Surg Am. 2003;85 Suppl 4:39-48.

8. Parratte S, Pagnano MW. Muscle damage during minimally invasive total hip arthroplasty: cadaver-based evidence that it is significant. Instr Course Lect. 2008;57:231-4.

9. Lovell TP. Single-incision direct anterior approach for total hip arthroplasty using a standard operating table. J Arthroplasty. 2008;23:64-8.

10. Barrett WP, Turner SE, Leopold JP. Prospective randomized study of direct anterior vs postero-lateral approach for total hip arthroplasty. J Arthroplasty. 2013;28:1634-8.

11. de Steiger RN, Lorimer M, Solomon M. What is the learning curve for the anterior approach for total hip arthroplasty? Clin Orthop Relat Res. 2015;473:3860-6.

12. Harris WH. Traumatic arthritis of the hip after dislocation and acetabular fractures: treatment by mold arthroplasty. An end-result study using a new method of result evaluation. J Bone Joint Surg Am. 1969;51:737-55.

13. Koval KJ, Skovron ML, Aharonoff GB, Meadows SE, Zuckerman JD. Ambulatory ability after hip fracture. A prospective study in geriatric patients. Clin Orthop Relat Res. 
1995;310:150-9.

14. Lewinnek GE, Lewis JL, Tarr R, Compere CL, Zimmerman JR. Dislocations after total hip-replacement arthroplasties. J Bone Joint Surg Am. 1978;60:217-20.

15. Chechik O, Khashan M, Lador R, Salai M, Amar E. Surgical approach and prosthesis fixation in hip arthroplasty world wide. Arch Orthop Trauma Surg. 2013;133:1595-600.

16. Post ZD, Orozco F, Diaz-Ledezma C, Hozack WJ, Ong A. Direct anterior approach for total hip arthroplasty: indications, technique, and results. J Am Acad Orthop Surg. 2014;22:595603.

17. Matta JM, Shahrdar C, Ferguson T. Single-incision anterior approach for total hip arthroplasty on an orthopaedic table. Clin Orthop Relat Res. 2005;441:115-24.

18. Keršič M, Dolinar D, Antolič V, Mavčič B. The impact of leg length discrepancy on clinical outcome of total hip arthroplasty: comparison of four measurement methods. J Arthroplasty. 2014;29:137-41.

19. Berend KR, Mirza AJ, Morris MJ, Lombardi AV Jr. Risk of periprosthetic fractures with direct anterior primary total hip arthroplasty. J Arthroplasty. 2016;31:2295-8.

20. Yu H, Liu H, Jia M, Hu Y, Zhang Y. A comparison of a short versus a conventional femoral cementless stem in total hip arthroplasty in patients 70 years and older. J Orthop Surg Res. 2016;11:33.

21. Dietrich M, Kabelitz M, Dora C, Zingg PO. Perioperative fractures in cementless total hip arthroplasty using the direct anterior minimally invasive approach: reduced risk with short stems. J Arthroplasty. 2018;33:548-54.

22. Learmonth ID. Conservative stems in total hip replacement. Hip Int. 2009;19:195-200.

23. Hartford JM, Knowles SB. Risk factors for perioperative femoral fractures: cementless femoral implants and the direct anterior approach using a fracture table. J Arthroplasty. 2016;31:2013-8.

24. van Dijk CM, Bimmel R, Haddad FS. (iv) Surgical approaches in primary total hip arthroplasty - pros and cons. Orthop Trauma. 2009;23:27-34. 


\section{일반 수술 침대와 짧은 대퇴 주대를 이용한 인공 고관절 전 치환술의 직접 전방 도달법과 변형된 전 측방 도달법에 따른 결과 비교

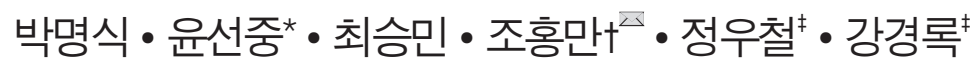

호성전주병원 정형외과, ${ }^{*}$ 전북대학교 의학전문대학원 정형외과학교실, ${ }^{\dagger}$ 광주보훈병원 정형외과, ${ }^{\ddagger}$ 성가롤로병원 정형외과

목적: 일반 수술용 침대와 길이가 짧은 대퇴 주대(short stem)를 이용하여 인공 고관절 전 치환술을 직접 전방 도달법(direct anterior approach, DAA)을 이용하여 시행하고, 임상적 영상의학적 결과를 변형된 전 측방 도달법(modified Hardinge; anterolateral approach, ALA)을 시행한 경우와 비교하여 알아보고자 하였다.

대상 및 방법: 2013년 1월부터 2015년 11월까지 단일 술자가 DAA로 인공 고관절 전 치환술을 시행한(DAA group) 102명(102예)과 동 수의 ALA를 사용한 환자(ALA group)를 후향적으로 비교 분석하였다. 수술시간과 출혈량을 비교하였고, 수술 후 통증의 개선 정 도와 보행 능력 및 고관절의 기능 회복을 알아보았다. 영상의학적으로 비구 컵과 대퇴 주대의 삽입 위치를 평가하였고, 두 군 간에 발 생한 합병증을 알아보았다.

결과: 출혈량은 $\mathrm{DAA}$ group에서 유의하게 적었다 $(\mathrm{p}=0.018)$. 수술 후 3 주까지는 하지 근력의 회복이 DAA group에서 유의하게 높았 다(굴곡/신전력 $\mathrm{p}=0.023$, 외전력 $\mathrm{p}=0.031$ ). Harris hip score를 이용한 기능 평가는 3 개월까지( $\mathrm{p} \leq 0.001)$, Koval score를 이용한 보 행 능력 평가는 6주까지 $(\mathrm{p} \leq 0.001) \mathrm{DAA}$ group에서 유의하게 나은 결과를 보였고, visual analogue scale score를 이용한 통증의 개선 은 7일까지는 DAA group에서 유의하게 높았다 $(\mathrm{p}=0.035)$. 비구 컵의 경사각 $(\mathrm{p} \leq 0.001)$ 과 전염각 $(\mathrm{p} \leq 0.001)$ 은 DAA group에서 ALA group보다 더 안정 범위에 위치하였고, 대퇴 주대의 위치와 하지 길이는 통계적 유의한 차이를 보이지 않았다. DAA group에서 수술 중 2예의 대전자 골절이 발생하였다( $\mathrm{p}=0.155)$.

결론: 길이가 짧은 대퇴 주대를 이용하여 일반 수술 침대에서 시행하는 DAA는 수술 후 조기 기능 회복을 보이며, 술자에게 친숙한 해부학적 자세로 수술 중 영상 증폭기 사용이 간편하여 원하는 위치에 인공 관절물을 삽입하는 것과 하지 부동 방지에 유용한 도달법 으로 생각된다.

색인단어: 인공 고관절 전 치환술, 직접 전방 도달법, 전 측방 도달법, 짧은 대퇴 주대, 일반 수술 침대

접수일 2018년 8월 7일 수정일 2018년 10월 2일 게재확정일 2018년 10월 2일

책임저자 조홍만

62284, 광주시 광산구 첨단월봉로 99, 광주보훈병원 정형외과

TEL 062-602-6162, FAX 062-602-6936, E-mail chm1228@hanmail.net, ORCID https://orcid.org/0000-0001-5160-2640 